\title{
Use of anionic denaturing detergents to purify insoluble proteins after overexpression
}

\author{
Benjamin Schlager*, Anna Straessle and Ernst Hafen
}

\begin{abstract}
Background: Many proteins form insoluble protein aggregates, called "inclusion bodies", when overexpressed in E. coli. This is the biggest obstacle in biotechnology. Ever since the reversible denaturation of proteins by chaotropic agents such as urea or guanidinium hydrochloride had been shown, these compounds were predominantly used to dissolve inclusion bodies. Other denaturants exist but have received much less attention in protein purification. While the anionic, denaturing detergent sodiumdodecylsulphate (SDS) is used extensively in analytical SDS-PAGE, it has rarely been used in preparative purification.
\end{abstract}

Results: Here we present a simple and versatile method to purify insoluble, hexahistidine-tagged proteins under denaturing conditions. It is based on dissolution of overexpressing bacterial cells in a buffer containing sodiumdodecylsulfate (SDS) and whole-lysate denaturation of proteins. The excess of detergent is removed by cooling and centrifugation prior to affinity purification. Host- and overexpressed proteins do not co-precipitate with SDS and the residual concentration of detergent is compatible with affinity purification on Ni/NTA resin. We show that SDS can be replaced with another ionic detergent, Sarkosyl, during purification. Key advantages over denaturing purification in urea or guanidinium are speed, ease of use, low cost of denaturant and the compatibility of buffers with automated FPLC.

Conclusion: Ionic, denaturing detergents are useful in breaking the solubility barrier, a major obstacle in biotechnology. The method we present yields detergent-denatured protein. Methods to refold proteins from a detergent denatured state are known and therefore we propose that the procedure presented herein will be of general application in biotechnology.

Keywords: Inclusion Bodies, Sodiumdodecylsulphate (SDS), N-lauroylsarcosine sodium salt (Sarkosyl), Immobilized Metal Ion Affinity Chromatography (IMAC)

\section{Background}

The purification of natively folded protein from heterologous expression systems is cumbersome and in some cases impossible because of the formation of insoluble protein aggregates called inclusion bodies [1]. Factorial screens of expression conditions or refolding assays can yield soluble proteins in some cases and can increase yield in most cases but many proteins remain resistant [2]. Affinity purification under denaturing conditions followed by renaturation can yield natively folded protein and is a viable alternative.

Anfinsen first demonstrated the reversible denaturation of proteins in solutions of urea in the 1960ies [3]. It has since been the method of choice to denature

\footnotetext{
* Correspondence: bschlage@ethz.ch

Institute for Molecular Systems Biology, ETH Zurich, Wolfgang Pauli-Strasse 16, Zurich 8093, Switzerland
}

native proteins and also aberrant protein aggregates. The denaturation of proteins by urea yields protein in a random coil state, i.e. no secondary structure elements are favoured over any other conformation [4]. The interactions of SDS with proteins have been intensively studied since the 1940ies [5-8]. Denaturation of polypeptides by SDS is a multi-step process that starts with the interaction of the negatively charged sulphate group with oppositely charged, basic, amino acid side chains [9]. The hydrophobic tails of SDS molecules then become buried in the hydrophobic core of proteins and start to disrupt the native structure [10-12]. Finally a large fraction of the polypeptide chain, independent of its conformation in the native state, adopts an alpha-helical conformation and is surrounded by a micelle of SDS molecules $[9,13]$. The length of this mixed protein-detergent micelle is roughly proportional to the molecular weight of the polypeptide [6]. 
Thus the denaturation of polypeptides by urea and SDS are different at the mechanistic level and yield two different results: a random-coil structure in urea and a largely alpha-helical conformation in SDS $[4,6]$.

Hexahistidine-tagged proteins can be purified under denaturing conditions using chaotropic concentrations of urea or guanidinium hydrochloride [14]. The highaffinity binding of the hexahistidine tag to Ni/NTA resin is based on the co-operative co-ordination of a nickel cation by two histidine side chains [14]. It is independent of the peptide conformation but requires close physical proximity (reviewed in [14]).

We wondered whether the histidine side chains of an SDS denatured protein, which are buried inside a mixed detegent-protein micelle, would be accessible for binding to Ni/NTA and whether thus detergent denatured proteins could be purfied by immobilized metal ion affinity chromatography (IMAC).

\section{Methods}

\section{Reagents and chemicals}

Phusion Polymerase was from New England Biolabs (Ipswich, USA). Cloning vector pET151/D-TOPO and BL21 cells were from Life Technologies (Zug, Switzerland). All chemicals used in this study were laboratory-grade. IPTG and SDS were from Carl Roth GmBH (Karlsruhe, Germany). DTT, imidazole and carbenicillin were from Applichem (Darmstadt, Germany). N-Lauroylsarkosine (Sarkosyl) was from Sigma-Aldrich (Steinheim, Germany) and NHS-activated Sepharose was from GE Healthcare Biosciences (Uppsala, Sweden). Purification was done on $5 \mathrm{ml}$ HisTrap columns from GE Healthcare Biosciences (Uppsala, Sweden). Precast SDS-PAGE gels were from LucernaChem (Luzern, Switzerland) and were stained with Coomassie Brilliant Blue as described elsewhere [15].

\section{Plasmid construction}

Expression constructs and their inserts are detailed in Table 1. cDNA was made from 0-6 hour old Drosophila melanogaster embryos or from Drosophila KC cells. Expression constructs were generated by blunt-end PCR amplification from cDNA using Phusion Polymerase. Amplified PCR fragments were cloned into pET151/DTOPO to generate expression constructs that express a $6 \mathrm{xHis}-\mathrm{V} 5-\mathrm{TEV}$ tagged fusion protein. All inserts were confirmed to be in-frame and full length by sequencing.

\section{Overexpression in E. coli}

Expression constructs were heat-shock transformed ino BL 21 (DE3) STAR cells, plated on LB plates containing carbenicillin $(50 \mu \mathrm{g} / \mathrm{ml})$ and incubated $\mathrm{o} / \mathrm{n}$ at $37^{\circ} \mathrm{C}$. The next day several colonies were collected and used to inoculate $300 \mathrm{ml}$ cultures of LB medium containing carbenicillin. The cultures were grown at $37^{\circ} \mathrm{C}$ until the $\mathrm{OD}$
600 was 0.5 and then induced by addition of IPTG to a final concentration of $0.5 \mathrm{mM}$. Cultures were then grown over night at $30^{\circ} \mathrm{C}$.

\section{Buffered solutions}

PCL (lysis buffer) contained $8 \mathrm{mM} \mathrm{Na} 2 \mathrm{HPO} 4,286 \mathrm{mM}$ $\mathrm{NaCl}, 1.4 \mathrm{mM} \mathrm{KH} 2 \mathrm{PO} 4,2.6 \mathrm{mM} \mathrm{KCl}$ and 1\% SDS (w/v) at $\mathrm{pH}$ 7.4. PCW (wash and equilibration buffer) contained $8 \mathrm{mM}$ Na2HPO4, $286 \mathrm{mM} \mathrm{NaCl}, 1.4 \mathrm{mM}$ $\mathrm{KH} 2 \mathrm{PO} 4,2.6 \mathrm{mM} \mathrm{KCl}$ and $0.1 \%$ Sarkosyl $(\mathrm{w} / \mathrm{v})$ at $\mathrm{pH}$ 7.4. PCE (elution buffer) contained $8 \mathrm{mM} \mathrm{Na2HPO4,}$ $286 \mathrm{mM} \mathrm{NaCl}, 1.4 \mathrm{mM} \mathrm{KH} 2 \mathrm{PO} 4,2.6 \mathrm{mM} \mathrm{KCl}, 500 \mathrm{mM}$ imidazole and 0.1\% Sarkosyl (w/v) at pH 7.4.

\section{Purification}

The cultures were harvested in GS3 rotor tubes by centrifugation at $4^{\circ} \mathrm{C}$ for 12 minutes at $6000 \mathrm{rpm}$. The pellet was resuspended in $30 \mathrm{ml}$ PCL buffer, supplemented with DTT to $1 \mathrm{mM}$, and sonicated with a Bandelin Sonoplus HD2070 sonicator, set to $80 \%$ cycle and $40 \%$ power using a MS73 probe-tip (Bandelin electronic, Berlin, Germany). Samples were sonicated at room temperature twice for 2 minutes each. The lysates were transferred to SS34 tubes and placed in an ice-water mixture and incubated for 30 minutes. The chilled lysates were then centrifuged in a SS34 rotor at $13 \mathrm{krpm}$ for 20 minutes at $4^{\circ} \mathrm{C}$. The cleared supernatant was poured off and filtered through a $0.45 \mu \mathrm{m}$ syringe filter before applying it to affinity purification. Ni/NTA affinity purification was performed on an AKTA Xpress FPLC system using $5 \mathrm{ml}$ HisTrap HP columns and standard purification templates (GE Healthcare Biosciences Uppsala, Sweden). Columns were equilibrated with PCW buffer, the lysate loaded and the columns washed until the absorption of post-column flowthrough returned to base levels. Bound proteins were eluted with a $100 \mathrm{ml}$ linear gradient of buffers PCL and PCE, from 0 to $50 \%$ buffer PCE, i.e. from 0 to $250 \mathrm{mM}$ imidazole in 20 column volumes. Weakly bound contaminating proteins typically eluted at $40 \mathrm{mM}$ imidazole, the peak maximum of hexahistidine tagged proteins was between 80 and $150 \mathrm{mM}$ imidazole.

Samples were taken at various points (see legend Figure 1) and loaded on SDS-PAGE gels according to the total volume of the fraction to make samples comparable. SDS PAGE was performed on $12 \% 17$-well gels according to the manufacturers recommendations. See Figure 1 for a Coomassie stained SDS-PAGE gel of one representative sample (Construct 173). See Figure 2 for samples of the final eluted fractions for all 17 proteins.

\section{Results}

Figures 1 and 2 present the purification of seventeen different fusion proteins of sizes between 13 and $54 \mathrm{kDa}$, 
Table 1 Expression constructs and details of inserts

\begin{tabular}{|c|c|c|c|c|}
\hline Plasmid number & Insert Protein Domain & Flybase Protein ID and AA range & Uniprot ID & MW of fusion protein in $\mathrm{kDa}$ \\
\hline \multirow[t]{2}{*}{165} & chico PH & chico-PA & Q9XTN2 & 15.6 \\
\hline & & $8-107$ & & \\
\hline \multirow[t]{2}{*}{166} & chico PTB & chico-PA & Q9XTN2 & 16.6 \\
\hline & & $122-235$ & & \\
\hline \multirow[t]{2}{*}{168} & Pi3K92E catalytic & Pi3K92E-PA & P91634 & 45.7 \\
\hline & & 726-1088 & & \\
\hline \multirow[t]{2}{*}{171} & PDK1 PH-like & Pdk1-PA & Q9W0V1 & 14.3 \\
\hline & & $593-680$ & & \\
\hline \multirow[t]{2}{*}{172} & Akt1 catalytic & Akt1-PA & Q8INB9 & 40.3 \\
\hline & & 189-509 & & \\
\hline \multirow[t]{2}{*}{173} & rictor REM & rictor-PA & Q9VWJ6 & 12.1 \\
\hline & & $827-896$ & & \\
\hline \multirow[t]{2}{*}{174} & Tor kinase catalytic & Tor-PA & Q9VK45 & 36.3 \\
\hline & & 2074-2352 & & \\
\hline \multirow[t]{2}{*}{175} & S6K catalytic & S6k-PA & P91656 & 39.2 \\
\hline & & $92-402$ & & \\
\hline \multirow[t]{2}{*}{176} & TSC2 Tuberin & gig-PA & Q9WW83 & 40.5 \\
\hline & & $561-883$ & & \\
\hline \multirow[t]{2}{*}{177} & TSC2 DUF 3384 & gig-PA & Q9WW83 & 54.3 \\
\hline & & $37-473$ & & \\
\hline \multirow[t]{2}{*}{178} & raptor WD & raptor-PA & Q9W437 & 47.9 \\
\hline & & $1210-1624$ & & \\
\hline \multirow[t]{2}{*}{179} & InR Y-kinase & InR-PA & P09208 & 36.7 \\
\hline & & $1363-1625$ & & \\
\hline \multirow[t]{2}{*}{180} & Akt1 PH-like & Akt1-PA & Q8INB9 & 16.0 \\
\hline & & 26-129 & & \\
\hline \multirow[t]{2}{*}{181} & foxo winged helix & foxo-PB & Q95V55 & 13.1 \\
\hline & & $95-175$ & & \\
\hline \multirow[t]{2}{*}{182} & Tor kinase DUF 3385 & Tor-PA & Q9VK45 & 22.8 \\
\hline & & 830-998 & & \\
\hline \multirow[t]{2}{*}{183} & Pi3K21B N-term SH2 & Pi3K21B-PA & 018683 & 16.6 \\
\hline & & 24-133 & & \\
\hline \multirow[t]{2}{*}{184} & Pi3K92E accessory & Pi3K92E-PA & P91634 & 24.6 \\
\hline & & $552-723$ & & \\
\hline
\end{tabular}

All constructs are based on pET151/D-TOPO. This vector contains a 6xHis-V5 Epitope - TEV cleavage sequence tag of approximately 4 kDa. The molecular weights given are those of the entire fusion protein, i.e. containing the tag.

detailed in Table 1. These proteins were previously shown to be insoluble after lysis of induced cells in standard native lysis buffers (PBS containing 0.5\% Triton X-100 or $0.3 \%$ Sarkosyl, data not shown). They are domains of proteins involved in the Drosophila Insulin and Tor Kinase signaling network and represent various non-homologous structures [16]. The purification of one of these protein domains, the REM domain of rictor, encoded by construct 173, is shown in detail in Figure 1. For the other sixteen proteins only the final, purified protein, is shown in Figure 2.
The hexahistidine-tagged proteins were overexpressed in E. coli using standard procedures (see Materials and Methods). After harvest the cells were resuspended and sonicated in a buffer containing high concentrations of SDS (34 mM, 1\% w/v). Proteins that aggregated in inclusion bodies were rapidly dissolved by sonication (see Figure 1, lane "L"). The lysates were then cooled to precipitate free SDS. The SDS pellet contained only small amounts of protein (see Figure 1, lane "P"). After centrifugation the supernatant contained both host proteins and overexpressed target protein (see Figure 1, lane "S", compare to 


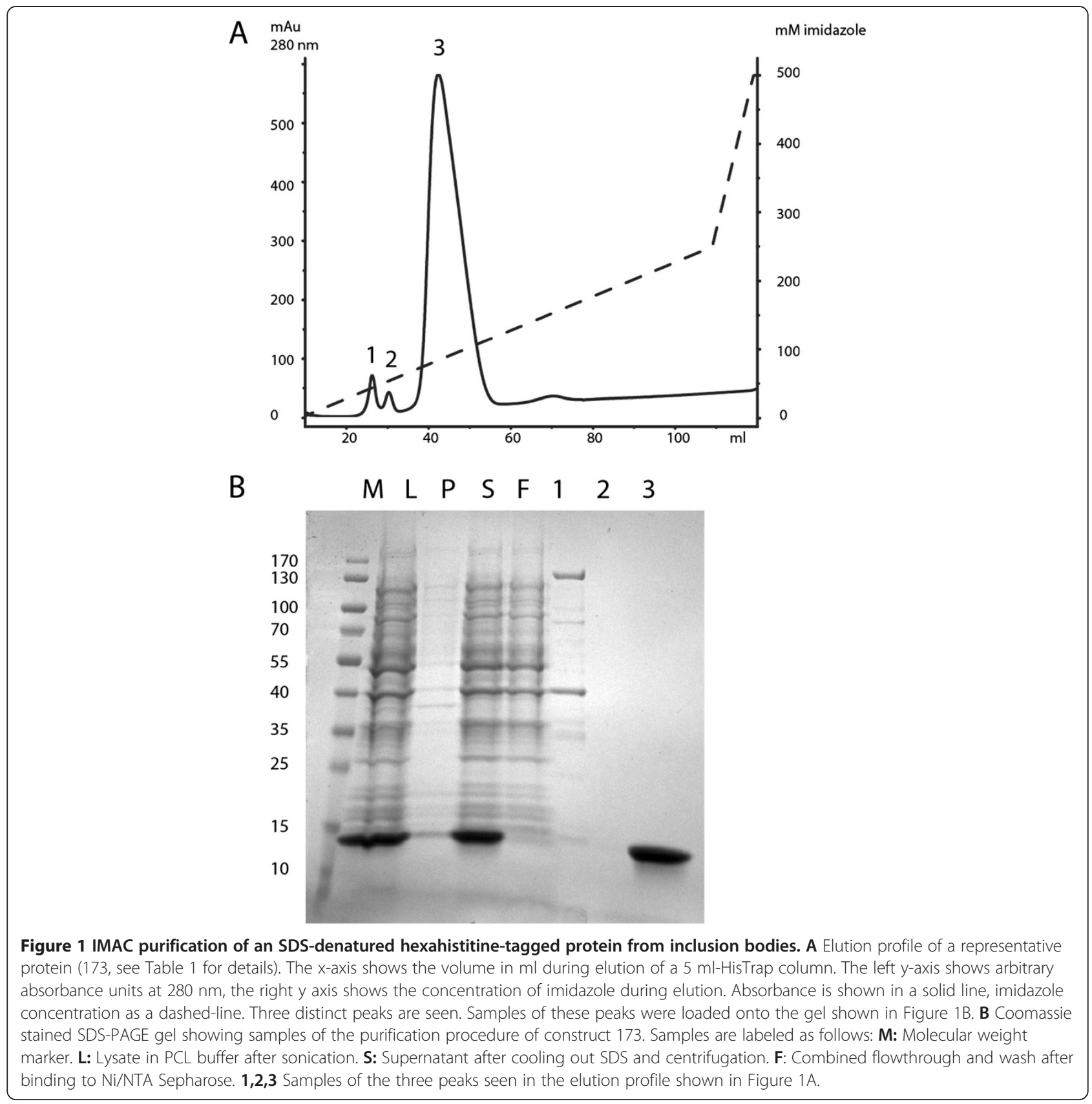

"L"). Thus proteins do not co-precipitate with SDS when the lysate is chilled. The lysates were then subjected to purification as detailed in Materials and Methods. The combined flow-through and wash fraction contained only minimal amounts of unbound fusion protein (see Figure 1, lane "F"). The elution profile shows three consecutive peaks eluting at $\pm 20,40$ and $90 \mathrm{mM}$ imidazole (Figure 1A). Table 2 summarizes the purification procedure.

\section{Discussion}

We wanted to test whether hexahistidine-tagged proteins can be IMAC-purified after SDS denaturation. In our first experiments we included $34 \mathrm{mM}(1 \% \mathrm{w} / \mathrm{v})$ of SDS in all buffers, i.e. in the lysis, wash and elution buffers commonly used for affinity purification. Cell pellets were rapidly lysed by sonication and binding to Ni/NTA resin occurred, however most of the hexahistidine-fusion protein was found in the flow-through, indicating poor binding (data not shown). Upon searching the literature we realized that there was no primary literature concerning the binding of hexahistidine-tagged proteins to $\mathrm{Ni}$ /NTA in solutions containing SDS. One manufacturer of Ni/NTA resins publishes a handbook that indicates that no more than $0.3 \%$ SDS should be included in the 


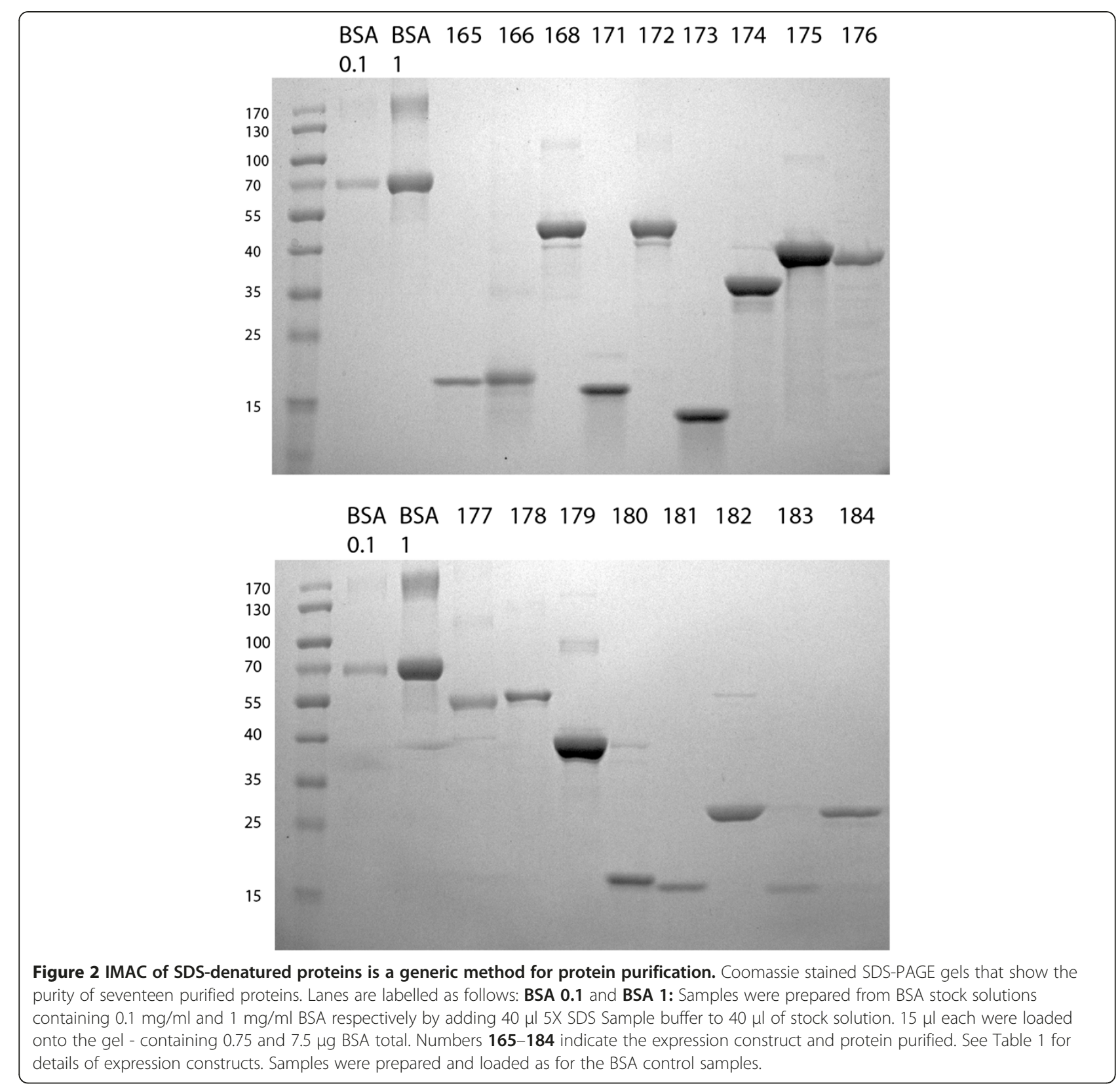

buffers [17] but these are empirical values that are not based on published experiments (QIAGEN AG, Basel Switzerland, pers. comm.).

In 1988 Suzuki and Terada published that SDS can be selectively removed from solutions containing BSA by cooling [8]. We hypothesized that the same principle might be applied to whole cell lysates and that it should yield a solution with lower concentrations of SDS that would be compatible with high affinity binding to $\mathrm{Ni}$ / NTA. We modified the buffer compositions such that only the buffer used for initial lysis contained high concentrations of SDS (34 mM, 1\% w/v) and included a low concentration of Sarkosyl (3 mM, 0.1\% w/v) in the wash and elution buffers. After lysis by sonication the lysate was cooled in an ice/water bath for 20 minutes and precipitated SDS removed by centrifugation. The residual concentration of SDS was compatible with high affinity binding to NI/NTA. We applied this purification protocol to seventeen different proteins (detailed in Results) and consistently achieved high-affinity binding and elution profiles that indicated sensitivity to imidazole concentration, i.e. contaminating proteins eluted at lower imidazole concentrations than the tagged target protein.

We would like to mention that we did not specifically test whether the dodecylsulphate anion (DS) of SDS precipitates as the sodium salt (SDS) or with another 
Table 2 Summary of the purification procedure

\begin{tabular}{|c|c|c|c|}
\hline Step & Description & Purpose & Comments \\
\hline 1 & $\begin{array}{l}\text { Growth, induction and } \\
\text { harvest of induced cells }\end{array}$ & $\begin{array}{l}\text { Overexpression of target protein in } E \text {. } \\
\text { coli }\end{array}$ & As described elsewhere [23] \\
\hline 2 & $\begin{array}{l}\text { Resuspension in } 1 \% \text { SDS } \\
\text { in PBS }\end{array}$ & Lysis of cells & $\begin{array}{l}\text { Works fine in } 1 / 20 \text { to } 1 / 10 \text { of the original culture volume. Other buffers } \\
\text { also work (50 mM Tris/Cl pH 7.0, } 100 \mathrm{mM} \mathrm{NaCl} \text { and } 1 \% \mathrm{SDS} \text { ) }\end{array}$ \\
\hline 3 & Sonication & $\begin{array}{l}\text { Solubilisation of proteins from } \\
\text { inclusion bodies }\end{array}$ & Until solution turns clear. Often faster than 2 minutes. \\
\hline 4 & $\begin{array}{l}\text { Incubation on ice for } \\
30 \text { minutes }\end{array}$ & Precipitation of SDS & $\begin{array}{l}\text { Precipitation of SDS apparent after } 5 \text { minutes. } 1 \mathrm{~h} \text { incubations on ice } \\
\text { possible. }\end{array}$ \\
\hline 5 & Centrifugation & Removal of precipitated SDS & SS34 rotor, $13 \mathrm{krpm}, 20$ minutes, $4^{\circ} \mathrm{C}$ \\
\hline 6 & $\begin{array}{l}\text { Ni/NTA affinity } \\
\text { purification }\end{array}$ & $\begin{array}{l}\text { Capture and washing of hexahistidine } \\
\text { tagged target protein }\end{array}$ & See M\&M for buffer compositions and details. \\
\hline 7 & Elution in $0.1 \%$ Sarkosyl & $\begin{array}{l}\text { Elution in a dialyzable detergent that is } \\
\text { compatible with refolding [24] }\end{array}$ & Other detergents could be used but were not tested. \\
\hline
\end{tabular}

Key steps in the procedure are described and their purpose briefly explained. The comments are based on the experiments described herein and additional purifications using the same principle but with slightly different protocols (altered buffers, volumes and incubation time on ice, data not shown).

monovalent cation such as potassium (KDS), which is also present in the buffer [8].

Detergents display complex phase diagrams in aqueous solutions [7]. Many detergents separate into a distinct phase when temperature or salt concentrations change. A landmark paper showed that integral membrane proteins remain in the detergent phase after temperature induced phase separation of Triton X-114 and that therefore phase separation can be used as a tool in protein purification [18]. Nowadays phase separation of detergents, sometimes called "cloud point extraction", is frequently used to purify membrane proteins [19].

We would like to point out that our method is similar to cloud point extraction only in as far as the detergent is used to initially solubilize the proteins of interest, in our case from inclusion bodies, and that phase separation is induced experimentally. However, it critically differs from cloud point extraction in that the proteins do not co-partition into the detergent phase after phase separation. Instead the surplus of unbound detergent is removed from the solution to allow subsequent affinity purification.

Curiously as early as in 1944 it was shown that SDS can be selectively removed from solutions containing proteins by cold precipitation with barium chloride [5]. Suzuki and Terada showed that SDS can be removed from solutions containing BSA by cooling [8], however, we are not aware of a publication that would combine this principle with the dissolution and denaturation of inclusion bodies and subsequent IMAC.

The buffer components used in this method are compatible with automated chromatography and allow high throughput purification of target proteins on a suitable purification platform. One key advantage over purification in urea or guanidinium is that SDS can be used at comparably low concentrations (34 $\mathrm{mM}$ versus 6-8 M) and does not tend to crystallize in valves and pumps of FPLC chromatographs [20].

Finally, we wish to add that protocols for the refolding of proteins from a detergent denatured state are known. One relies on replacing SDS with urea and subsequent removal of urea [21]. The other is based on cyclodextrine mediated stripping of detergent molecules from the protein [22]. We therefore think our method can be of application in the purification and refolding of recalcitrant proteins.

\section{Conclusion}

Ionic, denaturing detergents are useful reagents in the solubilization and purification of proteins from inclusion bodies and can be used to replace the more commonly used reagent urea.

Competing interests

The authors declare no competing financial interests.

\section{Authors' contributions}

AS cloned the expression constructs. BS planned and conducted all experiments and prepared the manuscript. All authors read and approved the final manuscript.

\section{Acknowledgements}

We thank Dirk Linke and Ari Helenius for discussions and pointing out important references. B.S. was supported by an EMBO Long Term Post Doctoral Fellowship.

Received: 17 October 2012 Accepted: 4 December 2012

Published: 11 December 2012

\section{References}

1. Frankel $S$, Sohn $R$, Leinwand $L$ : The use of sarkosyl in generating soluble protein after bacterial expression. Proc Natl Acad Sci USA 1991, 88:1192-1196.

2. Peti $W$, Page R: Strategies to maximize heterologous protein expression in Escherichia coli with minimal cost. Protein Expr Purif 2007, 51:1-10

3. Anfinsen $C B$, Haber E: Studies on the reduction and re-formation of protein disulfide bonds. J Biol Chem 1961, 236:1361-1363. 
4. Pace NC, Tanford C: Thermodynamics of the unfolding of beta-lactoglobulin $A$ in aqueous urea solutions between 5 and 55 degrees. Biochemistry 1968, 7:198-208.

5. Putnam F, Neurath $\mathrm{H}$ : The precipitation of proteins by synthetic detergents. J Am Chem Soc 1944, 66:692-697.

6. Tanford C: The hydrophobic effect: formation of micelles and biological membranes. New York: Wiley; 1973.

7. Linke D: Chapter 34 - detergents: An overview. 1st edition. Amsterdam, Netherlands: Elsevier Inc; 2009:603-617.

8. Suzuki H, Terada T: Removal of dodecyl sulfate from protein solution. Anal Biochem 1988, 172:259-263.

9. Jirgensons B: Effect of detergents on the conformation of proteins I. An abnormal increase of the optical rotatory dispersion constant. Arch Biochem Biophys 1961, 94:59-67.

10. Jones MN, Manley P: Binding of n-alkyl sulphates to lysozyme in aqueous solution. J Chem Soc Faraday Trans 1 1979, 75:1736.

11. Jones MN, Manley P, Holt A: Cooperativity and effects of ionic strength on the binding of sodium n-dodecyl sulphate to lysozyme. Int J Biol Macromol 1984, 6:65-68.

12. Nelson CA: The binding of detergents to proteins I. The maximum amount of dodecyl sulfate bound to proteins and the resistance to binding of several proteins. J Biol Chem 1971, 246:3895-3901.

13. Parker W, Song PS: Protein structures in SDS micelle-protein complexes. Biophys J 1992, 61:1435-1439.

14. Petty KJ: Metal-chelate affinity chromatography. Curr Protoc Mol Biol 2001, Chapter 10(Unit 10):11B

15. Nesatyy VJ, Dacanay A, Kelly JF, Ross NW: Microwave-assisted protein staining: mass spectrometry compatible methods for rapid protein visualisation. Rapid Commun Mass Spectrom 2002, 16:272-280.

16. Oldham S, Hafen E: Insulin/IGF and target of rapamycin signaling: a TOR de force in growth control. Trends Cell Biol 2003, 13:79-85.

17. QIAGEN: The QIAexpressionist A handbook for high-level expression and purification of 6xHis-tagged proteins. 5th edition. Switzerland: QIAGEN; 2003.

18. Bordier C: Phase separation of integral membrane proteins in Triton X-114 solution. J Biol Chem 1981, 256:1604-1607.

19. Arnold T, Linke D: Phase separation in the isolation and purification of membrane proteins. Biotech 2007, 43:427-440.

20. Sheehan D: Fast protein liquid chromatography (FPLC) methods. Methods Mol Biol 1996, 59:269-275.

21. Weber K, Kuter DJ: Reversible denaturation of enzymes by sodium dodecyl sulfate. J Biol Chem 1971, 246:4504-4509.

22. Rozema D, Gellman SH: Artificial chaperone-assisted refolding of carbonic anhydrase B. J Biol Chem 1996, 271:3478-3487.

23. Sambrook J, Russell DW: Molecular cloning. Cold Spring Harbor, New York: CSHL Press; 2001.

24. Burgess RR: Purification of overproduced Escherichia coli RNA polymerase sigma factors by solubilizing inclusion bodies and refolding from Sarkosyl. Meth Enzymol 1996, 273:145-149.

doi:10.1186/1472-6750-12-95

Cite this article as: Schlager et al: Use of anionic denaturing detergents to purify insoluble proteins after overexpression. BMC Biotechnology 2012 12:95.

\section{Submit your next manuscript to BioMed Central and take full advantage of:}

- Convenient online submission

- Thorough peer review

- No space constraints or color figure charges

- Immediate publication on acceptance

- Inclusion in PubMed, CAS, Scopus and Google Scholar

- Research which is freely available for redistribution 